\title{
Morphometric diagnosis of Glossina palpalis (Diptera: Glossinidae) population structure in Ghana
}

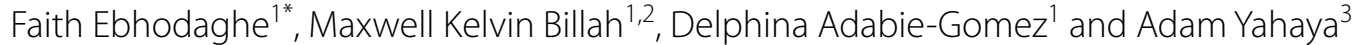

\begin{abstract}
Objective: This study aimed to identify isolated population(s) of Glossina palpalis in Ghana using geometric morphometrics to evaluate variations in wing-shape and size between populations of the fly from three regions.

Results: Wing shape of G. palpalis tsetse flies from the Northern, Western and Eastern Regions varied significantly between each other. Populations from the Northern and Western Regions varied the most (Mahalanobis Distance $=54.20$ ). The least variation was noticed between populations from the Western and Eastern Regions $(M D=1.99)$. On morphospace, the Northern population clearly separated from the Eastern and Western populations both of which overlapped. Wing centroid size also significantly varied among populations. Reclassification scores were satisfactory reaching $100 \%$ for the Northern population. The Northern population of G. palpalis is possibly isolated from the Western and Eastern Region populations. Meanwhile, a panmictic relationship could be on-going between the Western and Eastern populations. We speculate that geographical distance and subspecific difference between populations are among factors responsible for observed pattern of wing shape variations among the studied populations. The implications of results regarding choice of control strategy and limitations of the study are discussed.
\end{abstract}

Keywords: Ghana, Glossina palpalis, Population

\section{Introduction}

African trypanosomiasis is a disease of man and livestock in Sub-Saharan Africa. The disease constrains human and animal health, and retards socioeconomic development [1-3]. Infection with trypanosomes, the etiological agents of African trypanosomiasis, results through infective bites by tsetse flies during bloodmeals. To eliminate the problem of African trypanosomiasis, present control efforts are partly geared towards eradicating the tsetse fly vectors [4].

Tsetse eradication is more easily achievable on Islands than on mainlands. On Islands, tsetse populations are isolated and as a result can be readily targeted for elimination and eradication $[5,6]$. But on mainlands,

\footnotetext{
*Correspondence: ebhodaghefaith@gmail.com

${ }^{1}$ African Regional Postgraduate Programme in Insect Science,

West-African Sub-Regional Centre, University of Ghana Legon, Accra, Ghana

Full list of author information is available at the end of the article
}

populations are commonly panmictic. Consequently, reinfestation could result, that is, in a circumstance where only a subpopulation of an entire panmictic population was controlled $[4,7,8]$. However, in some cases, due to fragmentation of tsetse habitats by anthropogenic activities, climate differences etc., it is possible for tsetse populations to become isolated on mainlands. Thus, to reduce tsetse re-infestations on mainlands and therefore fasttrack their eradication, attempts are now being made to identify such isolated populations [9-12].

In Ghana, the human form of African trypanosomiasis was last reported in 2013 [13]. But the animal trypanosomiasis remains highly endemic and Glossina palpalis, which is perhaps the most spatially distributed tsetse fly species within the country, is the primary vector of the disease [14-16]. Insect wing morphometric properties are influenced by genes and, as a result, may provide information on tsetse population structure [7, 9, 11, 12]. Wing shape was used to investigate G. palpalis palpalis population structure in Ivory Coast [9]. In the 
study, seventy-nine percent (79\%) of wing shape variations between populations of the tsetse fly was explained by genetic variations after microsatellite DNA analysis. Wing morphometry also favourably compared with microsatellite DNA analysis in Guinea where the Loos Island G. p. gambiensis population was reportedly isolated from the mainland [11].

We therefore conducted a study to diagnose G. palpalis population structure for presence of isolated population(s) using the cost effective geometric morphometrics technique to assess for variations in wing morphometry (shape and size) among populations from three regions, namely, Northern, Western and Eastern Regions. The regions were selected on the basis of their location in different parts of the country which could present a clearer picture of G. palpalis population structure in Ghana than when an area of limited spatial coverage is considered.

\section{Main text}

\section{Tsetse fly populations and study areas}

The study populations were from the Northern and Southern sectors of Ghana. In the Northern sector, tsetse samples were collected from the Mole National Game Reserve in the Northern Region, while in the Southern sector, samples were from tsetse-endemic locations in the Eastern and Western Regions (Table 1; Fig. 1). The three regions occupy different ecological zones: Western Region is in the tropical rainforest zone; Eastern Region in the semi-deciduous rain forest zone; and the Northern Region in the savannah grassland. From the Southern to Northern Sector, temperature ranges from $18{ }^{\circ} \mathrm{C}$ to over $40{ }^{\circ} \mathrm{C}$, and annual rainfall from 2000 to $1100 \mathrm{~mm}$ [17].

\section{Collection of tsetse fly samples}

Tsetse flies were sampled in August to October, 2016. Biconical traps without attractants were used for the collection. We located traps within livestock producing areas in the Eastern and Western Regions, but along riparian vegetation in the Northern Region. Collected tsetse flies were harvested from traps after every $24 \mathrm{~h}$, while G. palpalis were morphologically identified [18], sorted into sexes, and stored in $70 \%$ alcohol within small labeled vials until morphometric analysis.

\section{Preparation of tsetse fly wings}

A total of 175 G. palpalis was analyzed using geometric morphometrics: 93, 53 and 29 flies from the Western, Eastern and Northern Regions, respectively (Table 1). Variations in number of flies analyzed for each region were influenced by number of flies collected and those whose wings remained intact and undamaged at the point of analysis. We considered only the right wings of female tsetse flies for analyses to avoid asymmetric and sexual dimorphic effects $[19,20]$.

Wings were detached from each fly and mounted in glycerol between glass slides and cover slips. Wing images were photographed at $12.5 \times$ magnification using an EZ4D microscope with an inbuilt camera connected to a laptop computer where captured images were archived.

\section{Data acquisition}

One individual collected 11 landmark coordinates on each wing image [21]. Landmarks were collected in the same order for each wing. Digitized image not displayed. See section on 'availability of data and materials' below.

\section{Geometric morphometric analysis Wing shape}

Raw landmark coordinates were transformed and superimposed by the Generalised Proscrustes method to generate shape variables by removing effects of scale, location, and orientation [22, 23]. Shape variables in the form of partial warps scores were subjected to discriminant analysis to produce Mahalanobis distances used to

Table 1 Study areas where tsetse fly samples were collected and number of tsetse flies used for analysis

\begin{tabular}{|c|c|c|c|c|c|c|c|}
\hline \multirow[t]{2}{*}{ Ecological Zone } & \multirow[t]{2}{*}{ Region } & \multirow[t]{2}{*}{ Collection site } & \multicolumn{2}{|l|}{ Coordinate } & \multirow[t]{2}{*}{ Altitude (m) } & \multirow[t]{2}{*}{ No. collected } & \multirow[t]{2}{*}{ No. analyzed } \\
\hline & & & Latitude (N) & Longitude (W) & & & \\
\hline \multirow[t]{4}{*}{ Tropical rainforest } & \multirow[t]{4}{*}{ Western } & Ahwake & $5^{\circ} 1^{\prime} 52^{\prime \prime}$ & $2^{\circ} 41^{\prime} 5^{\prime \prime}$ & 3 & 436 & 35 \\
\hline & & Allowule junction & $5^{\circ} 2^{\prime} 17^{\prime \prime}$ & $2^{\circ} 42^{\prime} 10^{\prime \prime}$ & 20 & 234 & 35 \\
\hline & & Nyame Kwame & $5^{\circ} 2^{\prime} 44^{\prime \prime}$ & $2^{\circ} 42^{\prime} 44^{\prime \prime}$ & 32 & 52 & 15 \\
\hline & & Nyanke & $5^{\circ} 3^{\prime} 14^{\prime \prime}$ & $2^{\circ} 42^{\prime} 4^{\prime \prime}$ & 7 & 95 & 8 \\
\hline \multirow[t]{3}{*}{ Semi-deciduous rainforest } & \multirow[t]{3}{*}{ Eastern } & Asuogya & $6^{\circ} 10^{\prime} 2^{\prime \prime}$ & $0^{\circ} 17^{\prime} 34^{\prime \prime}$ & 204 & 22 & 8 \\
\hline & & Kofikron & $6^{\circ} 10^{\prime} 29^{\prime \prime}$ & $0^{\circ} 18^{\prime} 57^{\prime \prime}$ & 190 & 68 & 39 \\
\hline & & Thomson village & $6^{\circ} 9^{\prime} 46^{\prime \prime}$ & $0^{\circ} 17^{\prime} 43^{\prime \prime}$ & 192 & 15 & 6 \\
\hline Savannah grassland & Northern & Mole reserve & $9^{\circ} 17^{\prime} 49^{\prime \prime}$ & $1^{\circ} 46^{\prime} 20^{\prime \prime}$ & 125 & 49 & 29 \\
\hline
\end{tabular}




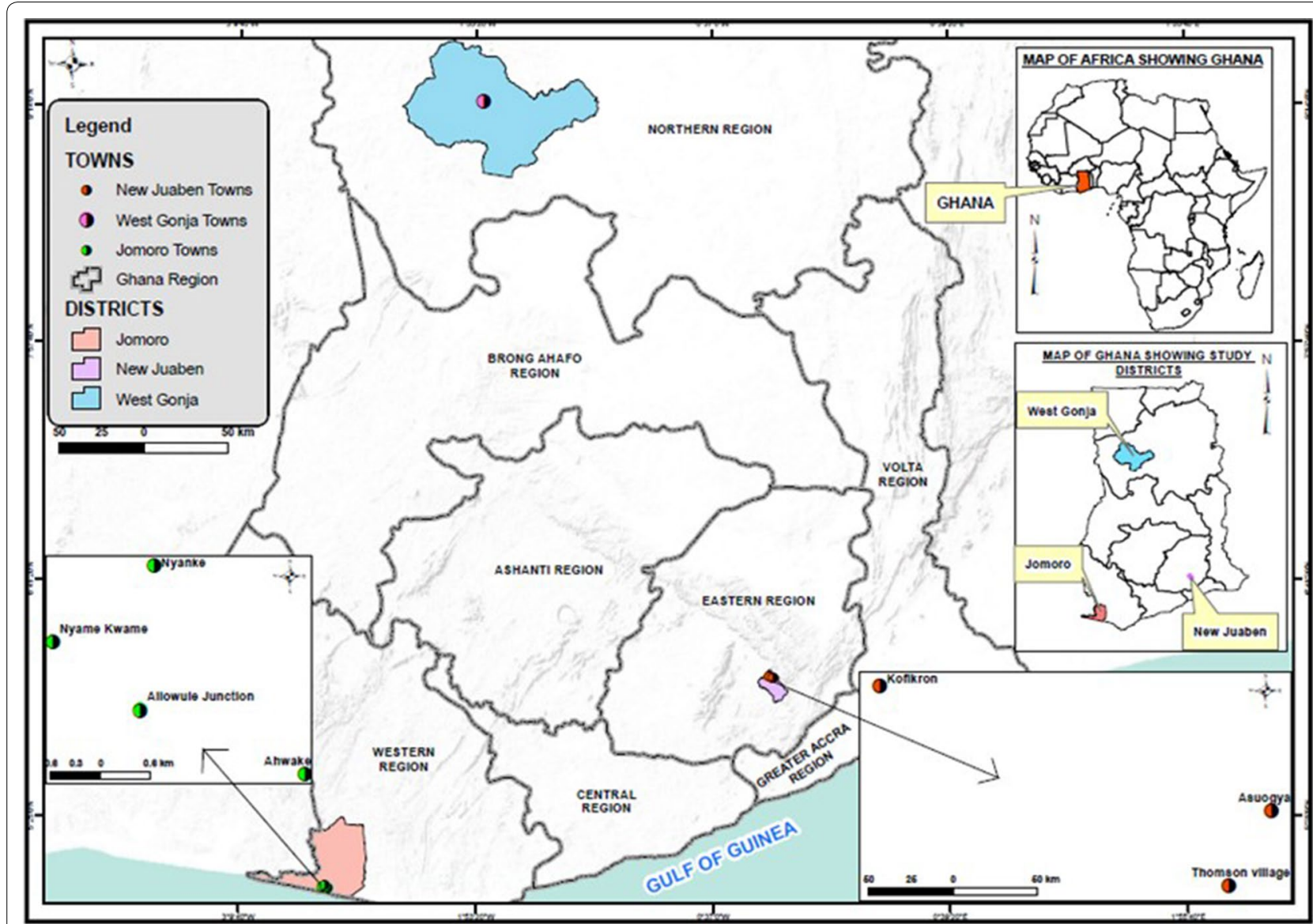

Fig. 1 Map of Ghana showing areas where tsetse flies were collected for geometric morphometric analysis. Map was designed by Ms. Nana Amah of the Remote Sensing and Geographic Information System Laboratory, University of Ghana Legon, Accra, Ghana

quantify wing shape variations between G. palpalis populations. Mahalanobis distances were tested for significant differences by the non-parametric method at 1000 permutations with Bonferroni's correction. $p$ value was significant at $<0.05$.

Morphospace was generated based on the first two canonical variates for graphical depiction of wing shape variations.

A reclassification test was performed to verify the accuracy of the geometric morphometric technique to correctly diagnose G. palpalis populations [24].

\section{Wing size}

Geometric morphometrics allows derivation of centroid sizes from landmark coordinates [25]. Centroid size is the square root of the sum of the squared distances between the center of the configuration of landmarks and each separate landmark. Significant difference in centroid sizes between populations was tested by the KruskalWallis test, while the Wilcoxon-rank-sum test was used for pairwise comparisons with Bonferroni $p$ value adjustment method at significant level of $\mathrm{p}<0.05$.

\section{Softwares}

Analyses were conducted in different modules of the CLIC package [23] and in R software (version 3.3.2).

\section{Results}

\section{Wing shape}

Mahalanobis Distances (MDs) were significantly different $(p<0.01667)$ between G. palpalis populations from the three study regions. The distance was highest between populations from the Northern and Western Regions (MD: 54.20), followed by Eastern and Northern Regions (MD: 53.44), and then Western and Eastern Regions (MD: 1.99). In each case, $p$-value was 0.000 .

Wing shape variations between populations were visualized on morphospace with the Northern population strongly separated from the other two populations (Fig. 2). However, Eastern and Western populations overlapped. 


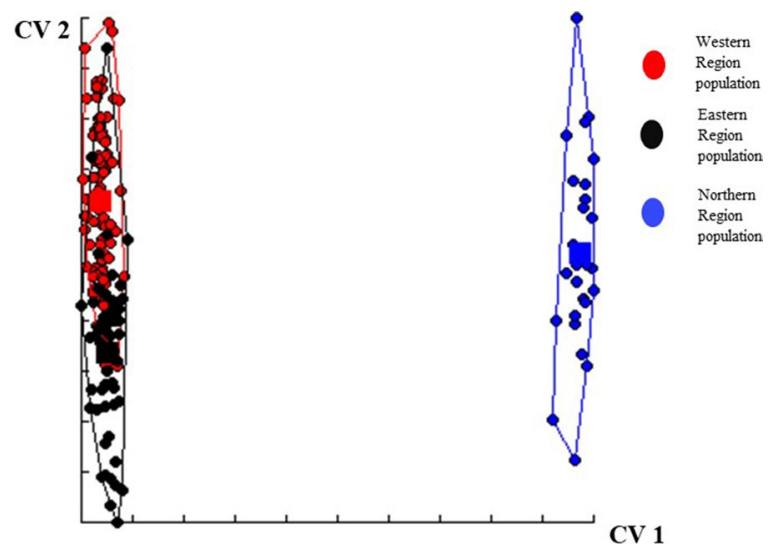

Fig. 2 Morphospace showing wing shape variation pattern of $G$. palpalis populations from Northern, Western, and Eastern Regions of Ghana. Morphospace is based on the first two Canonical Variates from discriminant analysis of wing shape variables. Convex hulls delimit extent of wing shape variations within population. Circular points represent individual tsetse flies. Tsetse flies of the same population are represented by same colour points. Squares within hulls represent average shape of a population. Overlapping of hulls representing populations from the Western (red) and Eastern (black) Regions indicates similarity in wing shape. Separation of hull representing population from the Northern Region (blue) signifies its dis-similarity in wing shape from the other populations

Reclassification scores were satisfactory, being highest for the Northern population (100\%). Reclassification scores for the Western and Eastern populations were 81 and $83 \%$, respectively.

\section{Wing size}

Overall mean centroid size was $568 \mathrm{~mm}$. Western population had the greatest centroid size of $590.33 \mathrm{~mm}$, followed by Eastern and Northern populations with centroid sizes of 567.90 and $496.97 \mathrm{~mm}$, respectively. Kruskal-Wallis test was significant (Chi squared value: 108.88. $\mathrm{p}<2.2 \times 10-16)$. Similarly, Wilcoxon-rank-sum tests between each pair of populations were also significant ( $p$ values: West vs. North: $<2 \times 10-16$. East vs. West: $1.8 \times 10-14$. North vs. West: < 2x10-16).

\section{Discussion}

The Northern population of G. palpalis was clearly isolated from other populations and thus can be targeted for elimination with little or no fear of re-infestation by populations from the Western or Eastern Regions. We also observed the Western and Eastern populations to be significantly different although, on morphospace, both populations overlapped suggesting panmixia. An attempt to sequentially control populations of the flies from these two regions may thus result in re-infestation. Therefore, both populations should be simultaneously controlled.
Geographical distance between the populations may have influenced observed pattern of segregation between populations [9]. The Northern and Western populations which were geographically farthest apart had the highest Mahalanobis distance, while the Western and Eastern populations which were closest had the least Mahalanobis distance. Similarly, in Ivory Coast, populations of G. p. palpalis within Abidjan when compared had low Mahalanobis distances [9]. Mahalanobis distances however increased when the Abidjan populations were compared to a population of the fly in Aniassue, an area of about $186 \mathrm{~km}$ away from Abidjan. Here, the locations of the study populations in the Western and Eastern Regions were 670 and $594 \mathrm{~km}$ respectively away from the Mole Game Reserve where tsetse were collected in the Northern Region. These long geographical distances from the Northern Region may have constrained exchange of genes between population from the Region and those from the Western and Eastern Regions.

More importantly, it is possible that the subspecific status of the populations contributed to their segregation. In Ghana, G. palpalis exists in two subspecific forms and these are Glossina palpalis palpalis in the rainforest zone $[14,16]$ and G. p. gambiensis in the savannah zone $[26,27]$. In view of this, we assumed that population of G. palpalis from the Northern Region belonged to the $G$. p. gambiensis subspecies for which cause, it clearly separated from the Western and Eastern populations which are presumably G. p. palpalis. Population segregation may have been further strengthened by variability in climatic conditions between the regions to which each population has become adapted [28, 29].

Centroid size was significantly higher in the Western than Eastern and Northern Regions. Temperature and relative humidity influence pupae sizes during development in the soil. Large tsetse individuals result from pupae which developed in low temperature soils, and the reverse in soils with high temperatures [9]. The low temperature and high humidity in the Western Region may have therefore caused the larger sizes of tsetse flies from the area. This idea is also expressed in a previous study [9] and agrees with the Bergmann's ecogeographical rule which states that organisms in low temperature areas have larger body sizes than their counterparts from high temperature locations.

Although wing shape and size were both significantly different between populations, the authors however recommend the use of wing shape in studies of tsetse population structure since it is more stable than size which could be easily influenced by changes in environmental variables [23].

The satisfactory reclassification scores obtained for each population indicates that geometric morphometrics 
which is cost effective could be an effective alternative, or more correctly, complementary approach to the molecular technique for diagnoses of tsetse population structure in Ghana $[24,30]$.

\section{Conclusion}

In the present study, we found a strong structuring of $G$. palpalis populations between the Northern and Southern sectors of Ghana but a likely ongoing panmixia between populations from the Eastern and Western Regions. Geographical distances between populations, subspecific differences, and non-uniform climatic conditions may be responsible for the observed structuring between populations. Whatever the case, our data support adoption of sequential control of G. palpalis populations between the Northern and Southern Sectors without fear of re-infestation, but simultaneous control in Eastern and Western Regions. Finally, considering the high reclassification scores obtained in this study and documented favourable comparison of geometric morphometrics with molecular tools, we recommend geometric morphometric study of wing shape as an efficient technique for tsetse population study in Ghana.

\section{Limitations}

A major limitation to this study was the non-utilization of molecular tools acclaimed to possess higher sensitivity than geometric morphometrics in tsetse population studies. Our non-utilization of molecular tools was due to unavailability of funds. Also, populations from the other five and two regions in southern and northern Ghana, respectively were not considered. Tsetse sampling activities are a costly endeavor thus we could only collect samples from three of the ten Regions of Ghana. Hopefully, these limitations would be addressed in the future pending availability of funds.

\section{Abbreviations \\ CLIC: collecting landmarks for identification and characterization; DNA: deoxy- ribonucleic acid; MD: Mahalanobis Distance; PATTEC: Pan African Tsetse and Trypanosomiasis Eradication Campaign.}

\section{Authors' contributions}

FE conceived the study, collected tsetse fly samples from field, performed analysis and wrote the paper. MKB and DAG supervised the study. AY provided logistic support. All authors read and approved the final manuscript.

\section{Author details \\ ${ }^{1}$ African Regional Postgraduate Programme in Insect Science, West-African Sub-Regional Centre, University of Ghana Legon, Accra, Ghana. ${ }^{2}$ Department of Animal Biology and Conservation Science, University of Ghana Legon, Accra, Ghana. ${ }^{3}$ Tsetse and Trypanosomiasis Control Unit/PATTEC, Ministry of Food and Agriculture, Pong-Tamale, Ghana.}

\section{Acknowledgements}

The authors appreciate staff of the National Tsetse and Trypanosomiasis Control Unit Accra and Pong-Tamale for assistance during collection of samples.
Competing interests

The authors declare that they have no competing interests.

Availability of data and materials

Digitized images of tsetse fly wings used in the current study are available from the corresponding author on reasonable request.

\section{Ethics approval and consent to participate}

Collection of tsetse fly samples received approval from the Ghana National Directorate of the Tsetse and Trypanosomiasis Control Unit (TTCU), Ministry of Food and Agriculture, Pong-Tamale, Northern Region of Ghana.

\section{Funding}

Not applicable.

\section{Publisher's Note}

Springer Nature remains neutral with regard to jurisdictional claims in published maps and institutional affiliations.

Received: 30 October 2017 Accepted: 21 December 2017

Published online: 29 December 2017

References

1. Swallow BM. Impacts of trypanosomiasis on African agriculture. Rome: FAO; 1999. p. 46.

2. Leta S, Alemayehu G, Seyoum Z, Bezie M. Prevalence of bovine trypanosomosis in Ethiopia: a meta-analysis. Parasites Vectors. 2016;9(1):139.

3. Mattioli RC, Slingenbergh J. Programme against African trypanosomiasis (PAAT) information system. 2013. http://www.fao.org/ag/AGAinfo/programmes/en/paat/disease.html.

4. Kuzoe FA, Schofield C. Strategic review of traps and targets for tsetse and African trypanosomiasis control.

5. Vreysen MJ, Saleh KM, Ali MY, Abdulla AM, Zhu ZR, Juma KG, Dyck VA, Msangi AR, Mkonyi PA, Feldmann HU. Glossina austeni (Diptera: Glossinidae) eradicated on the island of Unguja, Zanzibar, using the sterile insect technique. J Econ Entomol. 2000;93(1):123-35.

6. da Costa BF. Sleeping sickness; a record of four years' war against it in Principe, Portuguese West Africa. Lisbon: Centro colonial; 1916.

7. De Meeûs T, Ravel S, Rayaisse JB, Courtin F, Solano P. Understanding local population genetics of tsetse: the case of an isolated population of Glossina palpalis gambiensis in Burkina Faso. Infect Genet Evol. 2012;12(6):1229-34

8. Hargrove JW. A theoretical study of the invasion of cleared areas by tsetse flies (Diptera: Glossinidae). Bull Entomol Res. 2000;90(3):201-9.

9. Kaba D, Ravel S, Acapovi-Yao G, Solano P, Allou K, Bosson-Vanga H, Gardes L, N'Goran EK, Schofield CJ, Koné M, Dujardin JP. Phenetic and genetic structure of tsetse fly populations (Glossina palpalis palpalis) in southern Ivory Coast. Parasites Vectors. 2012;5(1):153.

10. Bouyer J, Ravel S, Guerrini L, Dujardin JP, Sidibé I, Vreysen MJ, Solano P, De Meeûs T. Population structure of Glossina palpalis gambiensis (Diptera: Glossinidae) between river basins in Burkina Faso: consequences for areawide integrated pest management. Infect Genet Evol. 2010;10(2):321-8.

11. Camara M, Caro-Riano H, Ravel S, Dujardin JP, Hervouet JP, De MeEüs T, Kagbadouno MS, Bouyer J, Solano P. Genetic and morphometric evidence for population isolation of Glossina palpalis gambiensis (Diptera: Glossinidae) on the Loos islands, Guinea. J Med Entomol. 2006:43(5):853-60.

12. Achukwi MD, Gillingwater J, Nloga AM, Simo G. Lack of evidence for sufficiently isolated populations of Glossina morsitans submorsitans on the Adamawa Plateau of Cameroon following geometric morphometric analysis. Adv Entomol. 2013;1(01):1.

13. Franco JR, Cecchi G, Priotto G, Paone M, Diarra A, Grout L, Mattioli RC, Argaw D. Monitoring the elimination of human African trypanosomiasis: update to 2014. PLoS Negl Trop Dis. 2017;11(5):e0005585.

14. Bauer B, Holzgrefe B, Mahama Cl, Baumann MP, Mehlitz D, Clausen PH. Managing tsetse transmitted trypanosomosis by insecticide treated 
nets - an affordable and sustainable method for resource poor pig farmers in Ghana. PLoS Negl Trop Dis. 2011;5(10):e1343.

15. Nakayima J, Nakao R, Alhassan A, Mahama C, Afakye K, Sugimoto C. Molecular epidemiological studies on animal trypanosomiases in Ghana. Parasites Vectors. 2012;5(1):217.

16. Apaatah F. Trypanosome prevalence in pigs and tsetse flies from Jomoro District in the Western Region of Ghana (M. Phil thesis, University of Ghana). 2014. p. 113.

17. Ghana Environmental Protection Agency, 2001.Temperature, rainfall, prevailing weather conditions, when to go, what to pack. Retrieved online from: https://www.climatestotravel.com/climate/ghana. Accessed 27 Dec 2017.

18. Pollock JN, editor. Training manual for tsetse control personnel: tsetse biology, systematics and distribution, techniques. Rome: FAO; 1982.

19. Virginio F, Vidal PO, Suesdek L. Wing sexual dimorphism of pathogenvector culicids. Parasites Vectors. 2015;8(1):159.

20. Solano P, De La Rocque S, Cuisance D, Geoffroy B, De Meeus T, Cuny G, Duvallet $G$. Intraspecific variability in natural populations of Glossina palpalis gambiensis from West Africa, revealed by genetic and morphometric analyses. Med Vet Entomol. 1999;13(4):401-7.

21. Dujardin JP, Kaba D, Henry AB. The exchangeability of shape. BMC Res Notes. 2010:3(1):266.

22. Rohlf FJ, Slice D. Extensions of the Procrustes method for the optimal superimposition of landmarks. Syst Biol. 1990;39(1):40-59.

23. Dujardin JP. Modern morphometrics of medically important insects. In: Tibayrenc M, editor. Genetics and evolution of infectious diseases. Amsterdam:Elsevier; 2011. p. 473-501.
24. Jaramillo-O N, Dujardin JP, Calle-Londoño D, Fonseca-González I. Geometric morphometrics for the taxonomy of 11 species of Anopheles (Nyssorhynchus) mosquitoes. Med Vet Entomol. 2015;29(1):26-36.

25. Zelditch ML, Swiderski DL, Sheets HD. Geometric morphometrics for biologists: a primer. New York: Academic Press; 2012.

26. Adam Y, Marcotty T, Cecchi G, Mahama Cl, Solano P, Bengaly Z, Van den Bossche P. Bovine trypanosomosis in the Upper West Region of Ghana: entomological, parasitological and serological cross-sectional surveys. Res Vet Sci. 2012;92(3):462-8.

27. Challier A, Gouteux JP, Coosemans M. La limite géographique entre les sous-espèces Glossina palpalis palpalis (Rob-Desv.) et G. palpalis gambiensis Vanderplank (Diptera: Glossinidae) en Afrique occidentale. CahiersORSTOM. Entomologie médicale et parasitologie. 1983;21(4):207-20.

28. Vidal PO, Carvalho E, Suesdek L. Temporal variation of wing geometry in Aedes albopictus. Mem Inst Oswaldo Cruz. 2012;107(8):1030-4.

29. Schachter-Broide J, Gürtler RE, Kitron U, Dujardin JP. Temporal variations of wing size and shape of Triatoma infestans (Hemiptera: Reduviidae) populations from northwestern Argentina using geometric morphometry. J Med Entomol. 2009;46(5):994-1000.

30. Kaba D, Berté D, Ta BT, Tellería J, Solano P, Dujardin JP. The wing venation patterns to identify single tsetse flies. Infect Genet Evol. 2017;31(47):132-9.

\section{Submit your next manuscript to BioMed Central and we will help you at every step:}

- We accept pre-submission inquiries

- Our selector tool helps you to find the most relevant journal

- We provide round the clock customer support

- Convenient online submission

- Thorough peer review

- Inclusion in PubMed and all major indexing services

- Maximum visibility for your research

Submit your manuscript at www.biomedcentral.com/submit 